\title{
Endocervical Swab Microbial Isolates among Women with Third Degree Uterovaginal Prolapse
}

\author{
K. C. Ekwedigwe, I. Sunday-Adeoye, M. E. Isikhuemen*, M. O. Eliboh, A. B. C. Daniyan, \\ E. N. Yakubu, I. C. Amamilo
}

National Obstetric Fistula Centre, Abakaliki, Nigeria

Email: *maradona4real2002@yahoo.com

How to cite this paper: Ekwedigwe, K.C., Sunday-Adeoye, I., Isikhuemen, M.E., Eliboh, M.O., Daniyan, A.B.C., Yakubu, E.N. and Amamilo, I.C. (2017) Endocervical Swab Microbial Isolates among Women with Third Degree Uterovaginal Prolapse. Open Journal of Obstetrics and Gynecology, 7, 369-375.

https://doi.org/10.4236/ojog.2017.73038

Received: January 10, 2017

Accepted: March 26, 2017

Published: March 29, 2017

Copyright $\odot 2017$ by authors and Scientific Research Publishing Inc. This work is licensed under the Creative Commons Attribution International License (CC BY 4.0).

http://creativecommons.org/licenses/by/4.0/

\begin{abstract}
Background: Uterovaginal prolapse is the descent of the uterus through the vaginal canal. This may be a predisposing factor to infections in the urogenital system. This study aimed to assess the endocervical swab microscopy, culture and sensitivity in patients with third degree uterovaginal prolapse at the $\mathrm{Na}$ tional Obstetric Fistula Centre, Abakaliki, South-East Nigeria. Methodology: This is a cross-sectional prospective study to assess the endocervical swab microbial findings in patients with third degree uterovaginal prolapse using simple random sampling technique. Data on sociodemographic variables, risk factors for pelvic organ prolapse, and endocervical swab findings among women with third degree uterovaginal prolapse were collated and analysed using statistical methods. Results: The mean age and parity were 50.5 years \pm 9.1 and $6.7 \pm 2.0$ respectively. Thirty-six $(85.7 \%)$ of the clients were grandmultipara and 37 (88.1\%) were farmers. Pus cells were present in all samples while $27(64.3 \%)$ had microbial isolates. Streptococcus pyogenes was isolated in 7 (16.7\%), Streptococcus faecalis in 5 (11.9\%), Escherichia coli in 5 (11.9), Staphylococcus aureus in $4(9.5 \%)$, Klebsiella pneumoniae in $2(4.8 \%)$ and Yeast cells in 4 (9.5\%) of the endocervical swabs. All isolates were sensitive to gentamicin. Bacterial isolates were resistant to amoxicillin/clavulanic acid. Conclusion: This study showed growth of pathogenic organisms from the endocervix of women with third degree uterovaginal prolapse. A $100 \%$ sensitivity to gentamicin was observed in the study.
\end{abstract}

\section{Keywords}

Uterovaginal Prolapse, Endocervical Swab, Microscopy, Culture, Sensitivity

\section{Introduction}

Uterovaginal prolapse is the descent of the uterus through the vaginal canal [1]. 
Its prevalence is difficult to estimate since some women may be asymptomatic. Multiparity is an important risk factor in our environment [2]. It is a significant cause of psychosexual and social burden to the affected women [3].

Herniation of the pelvic organs may predispose it to infection since the involved organs will be outside their usual anatomical confines. The herniating organs may also become close to the anal opening thereby predisposing such patients to infections. Some of these women with uterovaginal prolapse may even have decubitus ulcers which will further make them at risk of infections. It may be important to treat these patients so as to prevent ascending infections.

There are limited studies on the microbial pattern of endocervical swab in patients with uterovaginal prolapse if any. However a study done in Osogbo, Nigeria among patients suspected to have pelvic inflammatory disease, endocervical swab specimens revealed that $70 \%$ of patients had positive microbial growth [4]. Bacterial growth in endocervical swab was found in $19.5 \%$ of HIV positive patients in another study done in Nigeria [5].

Our aim in this study was to assess the endocervical swab microscopy, culture and sensitivity among patients with third degree uterovaginal prolapse at the National Obstetric Fistula Centre, Abakaliki, Nigeria.

\section{Methodology}

\subsection{Study Area}

The study was carried out at the National Obstetric Fistula Centre, Abakaliki, Nigeria. Abakaliki is the capital of Ebonyi state and the main occupation of its people is farming. It is an important producer of rice for the country. The Fistula Centre offers free surgical services to patients with urogenital fistula. It is a training centre for health workers and also has the responsibility of rehabilitation of fistula patients post repair. The centre is designated for screening and treatment of premalignant lesions of the cervix and breast, as well as family planning services in the south eastern region of the country. There is also a pool section for pelvic organ prolapse surgery. The centre has a bed space capacity of 96.

\subsection{Study Design}

A cross-sectional analytical study was done.

\subsection{Study Population}

Women with pelvic organ prolapse presenting at the National Obstetric Fistula Centre, Abakaliki, Nigeria for surgery were recruited for the study.

\subsection{Inclusion Criteria}

Patients with third degree uterovaginal prolapse who gave consent for the study.

\subsection{Exclusion Criteria}

Those with first and second degree uterovaginal prolapse. 


\subsection{Study Duration}

The study was conducted between September 2014 and October 2014.

\subsection{Scope of the Study}

This study focused on findings of the microbial isolates in women with third degree uterovaginal prolapse.

\subsection{Sample Size Determination}

The sample size was calculated by a statistical formula based on the proportion of $2.1 \%$ for women with uterine prolapse from a study done in Enugu, Nigeria, [6] and a confidence level set at $95 \%$ with an error margin of 0.05 .

$$
\mathrm{N}=\frac{\mathrm{PQ}}{(\mathrm{E} / 1.96)^{2}}
$$

where:

$\mathrm{N}$ is the sample size

1.96 is a known constant (Standard normal deviate corresponding to 95\% confidence level).

$\mathrm{P}$ is proportion of respondents with uterine prolapse $[6]=2.1 \%$

$\mathrm{Q}$ is $1-\mathrm{P}$ (proportion of the persons free from the disease) $=0.962$

$\mathrm{E}$ is the error margin $=0.05$

$\mathrm{N}=32$

However, a total of 42 patients were used for this study

\subsection{Sampling Technique}

Simple random sampling technique was used.

\subsection{Data Collection}

Following informed consent, a questionnaire was used to obtain relevant sociodemographic and clinical parameters from each participant. Endocervical swabs were taken and cultured on Blood and Chocolate agar. The antibiotic sensitivity test was done for isolated pathogenic bacteria. The antibiotics tested were gentamicin, ciprofloxacin, erythromycin, chloramphenicol, amoxycillin/clavulanic acid, ofloxacin, nitrofurantoin, streptomycin and co-trimoxazole.

\subsection{Data Analysis}

Collected data was entered and analyzed using Statistical Package for Social Sciences (SPSS) version 20.

\subsection{Ethical Consideration}

Ethical approval was obtained from Ethical Committee of the National Obstetric Fistula Centre, Abakaliki, Nigeria before commencement of the study. Participation was purely voluntary. Confidentiality was respected during the study. 


\section{Results}

The mean age and parity were 50.5years \pm 9.1 and $6.7 \pm 2.0$ respectively. Thirtysix $(85.7 \%)$ of the clients were grandmultipara and $37(88.1 \%)$ were farmers. Most of the respondents had no formal education. They were mostly rural dwellers with low socioeconomic status. Table 1 shows the sociodemographic variables of the study population.

Most patients had no history of chronic cough, 2 (4.8\%) had history of instrumental vaginal delivery and $6(14.3 \%)$ had history of pelvic surgery (Table 2). Many patients (42.9\%) had urinary symptoms.

There were pus cells in all the specimens. Twenty-seven patients (64.3\%) had microbial isolates. The organisms implicated were Streptococcus pyogenes in 7 (16.7\%), Streptococcus faecalis in 5 (11.9\%), Escherichia coli in 5 (11.9), Staphylococcus aureus in 4 (9.5\%), Klebsiella pneumoniae in 2 (4.8\%) and Yeast cells in 4 (9.5\%) of the endocervicalswabs (Table 3 ).

All isolates were sensitive to gentamicin and resistance to amoxicillin/clavulanic acid was $100 \%$ (Table 4 ).

Table 1. Sociodemographic variables.

\begin{tabular}{cccc}
\hline & & $\mathbf{n}=\mathbf{4 2}$ & $\%$ \\
\hline \multirow{3}{*}{ Age } & $30-39$ & 3 & 7.1 \\
& $40-49$ & 15 & 35.7 \\
\multirow{3}{*}{ Parity } & $50-59$ & 13 & 31 \\
& $>59$ & 11 & 26.2 \\
Marital Status & $2-4$ & 6 & 14.3 \\
& $>4$ & 36 & 85.7 \\
Level of Education & MARRIED & 40 & 95.2 \\
& WIDOW & 2 & 4.8 \\
& NO FORMAL EDUCATION & 36 & 85.7 \\
& PRIMARY & 1 & 2.4 \\
Occupation & PECONDARY & 1 & 2.4 \\
& FOST SECONDARY & 4 & 9.5 \\
& FARMING & 37 & 88.1 \\
& CIVIL SERVANT & 5 & 11.9 \\
\hline
\end{tabular}

Table 2. Risk factors for prolapse.

\begin{tabular}{cccc}
\hline & & $\mathbf{n}=\mathbf{4 2}$ & $\%$ \\
\hline \multirow{2}{*}{ Chronic Cough } & YES & 2 & 4.8 \\
& NO & 40 & 95.2 \\
Instrumental vaginal delivery & YES & 2 & 4.8 \\
pelvic surgery & NO & 40 & 95.2 \\
& YES & 6 & 14.3 \\
& NO & 36 & 85.7 \\
\hline
\end{tabular}


Table 3. Microscopy and culture result.

\begin{tabular}{cccc}
\hline & Microbial isolate & $\mathbf{n}=\mathbf{4 2}$ & $\%$ \\
\hline \multirow{2}{*}{ MICROSOPY } & PRESENT & 27 & 64.3 \\
& ABSENT & 15 & 35.7 \\
& STREPT PYOGENES & 7 & 16.7 \\
& STAPH AUREUS & 4 & 9.5 \\
CULTURE & STREPT FAECALIS & 5 & 11.9 \\
& KLEBSIELLA & 2 & 4.8 \\
& PNEUMONIAE & 4 & 9.5 \\
& YEAST CELLS & 5 & 11.9 \\
& E COLI & 15 & 35.7 \\
\hline
\end{tabular}

Table 4. Sensitivity pattern of microbial isolates.

\begin{tabular}{lccc}
\hline ERYTHROMYCIN & & $\mathbf{n}=\mathbf{2 7}$ & $\%$ \\
\hline CHLORAMPHENICOL & resistant & 16 & 59.3 \\
NITROFURANTION & sensitive & 11 & 40.7 \\
& resistant & 24 & 88.9 \\
AMOXICILLIN/CLAVULANIC ACID & sensitive & 3 & 11.1 \\
& resistant & 22 & 81.5 \\
COTRIMOXOZOLE & sensitive & 5 & 18.5 \\
& resistant & 27 & 100 \\
CIPROFLOXACIN & sensitive & 0 & 0 \\
& resistant & 24 & 88.9 \\
GENTAMYCIN & sensitive & 3 & 11.1 \\
& resistant & 23 & 85.2 \\
STREPTOMYCIN & sensitive & 4 & 14.8 \\
& resistant & 0 & 0 \\
OFLOXACIN & sensitive & 27 & 100 \\
& resistant & 19 & 70.4 \\
& sensitive & 8 & 29.6 \\
& resistant & 24 & 88.9 \\
& sensitive & 3 & 11.1 \\
\hline & &
\end{tabular}

\section{Discussion}

Uterovaginal prolapse is a source of worry to the gynaecologist. It is a significant cause of psychosexual problems [3]. Patients with this disease condition may be at increased risk of infection because the anatomy of the organs involved has probably been distorted.

In this study, the mean age was 50.5 years \pm 9.1 and this is similar to that reported from a related study from Enugu, South-East Nigeria [7]. These findings may be due to decreased levels of oestrogen and genital atrophy in this age group [7]. These findings are also similar to a previous study done in this setting [3]. 
Other studies have equally demonstrated grand multiparity as a risk factor for uterovaginal prolapse [3] [7] [8]. Repeated pregnancy and childbirth may result in stretching, weakening and sometimes denervation of the structures that provide support to the female genital tract [3]. Other risk factors for pelvic organ prolapse identified in this study were chronic cough, instrumental vaginal delivery and pelvic surgery.

From our study, microbial isolates were recorded in $64.3 \%$ of patients. There was no pathogenic organism isolated in $35.7 \%$ of patients. Major microbial growths were Streptococcus pyogenes, Streptococcus faecalis, Escherichia coli and Staphylococcus aureus. The risk factor for microbial growth in these patients may be due to distorted normal anatomy thereby exposing the cervix to the exterior. Also, the vaginal flora that was originally dominated by lactobacillus in the reproductive age group may now become populated by pathogenic microorganisms. Similarly, a study done among patients with suspected pelvic inflammatory disease in Osogbo, Nigeria using endocervical swab revealed that $70 \%$ of patients were positive for infection [4]. In another study done in Nigeria endocervical swab samples had positive bacteria isolates in $19.5 \%$ of patients. Microbial isolates in our study that have also been found in other studies done in Nigeria includes Staphylococcus aureus, Klebsiella pneumoniae and Escherichia coli [4] [5]. Another study done in rural Lebanon recorded a low incidence of urinary tract infection (3.8\%) using urine culture in women with genital prolapse [9].

There was a $100 \%$ sensitivity to gentamicin and $100 \%$ resistance to amoxicillin/clavulanic acid. This antibiotic sensitivity pattern is of great importance in low resource settings especially in situations where laboratory services may not be readily available. A high level of resistance of Staphylococcus aureus to amoxicillin was recorded in a study done is a similar setting [10].

This study is limited by its small sample size. Other drugs that are available in our setting were not also included in this study. This should direct future research.

\section{Conclusion}

This study revealed a high level of microbial isolate among women with third degree uterovaginal prolapse. There was $100 \%$ sensitivity to gentamicin and $100 \%$ resistance to amoxicillin/clavulanic acid. In low resource settings where effective laboratory services may not readily be available, findings of this study may be a useful guide to the choice of antibiotics in situations where pelvic infection appears postoperatively. Clinicians also need to be aware that amoxicillin/clavulanic acid may not be effective in preventing post operative infections following surgery for third degree uterovaginal prolapse

\section{References}

[1] Lazarou, G. (2016) Uterine Prolapse. Medscape 2016. Available from emedicine.medscape.com. Assassed 27/12/16. 
[2] Scherf, C., Morison, L., Fiander, A., Ekpo, G. and Walraven, G. (2002) Epidemiology of Pelvic Organ Prolapse in Rural Gambia, West Africa. BJOG, 109, 431-436. https://doi.org/10.1111/j.1471-0528.2002.01109.x

[3] Sunday-Adeoye, I., Ekwedigwe, K., Daniyan, B., Okonta, P. and Elibor, O. (2015) Pelvic Organ Prolapse: A Significant Cause of Psychosexual and Social Burden. Sky Journal of Medicine and Medical Sciences, 3, 067-070.

[4] Olowe, O.A., Alabi, A. and Akindele, A. (2012) Prevalence and Pattern of Bacterial Isolates in Cases of Pelvic Inflammatory Disease Patients at a Tertiary Hospital in Osogbo, Nigeria. Environmental Research Journal, 6, 308-311. https://doi.org/10.3923/erj.2012.308.311

[5] Charanchi, S., Kudi, A. and Tahir, F. (2012) Antimicrobial Sensitivity Patterns of Urogenital Bacterial Isolates among HIV Positive Patients in the Federal Medical Centre in Gombe. The Internet Journal of Infectious Diseases, 10, 1.

[6] Okonkwo, J.E.N., Obiechina, N.J.A. and Obionu, C.N. (2003) Incidence of Pelvic Organ Prolapse in Nigerian Women. Journal of the National Medical Association, 95, 132-136.

[7] Okeke, T.C., Ani, V.C., Ezenyeaku, C.C.T., Ikeako, L.C., Enwereji, J.O. and Ekwuazi, K. (2013) An Audit of Uterovaginal Prolapse in Enugu, Southeast Nigeria. American Journal of Clinical Medicine Research, 1, 23-25. https://doi.org/10.12691/ajcmr-1-1-6

[8] Rabiu, K.A., Adewunmi, A.A., Badmus, S.A., Akinola, O.I. and Akinlusi, F.M. (2009) Pelvic Organ Prolapse in Lagos, Nigeria. Nigerian Journal of Clinical Medicine, $2,2$.

[9] Deeb, M.E., Awwad, J., Yeretzian, J.S. and Kaspar, H.G. (2003) Prevalence of Reproductive Tract Infections, Genital Prolapse and Obesity in a Rural Community in Lebanon. Bulletin of the World Health Organization, 81, 639-645.

[10] Adekunle, O.T., Shittu, O.B., Alabi, B.L., Ogunfolakan, O.O. and Ogundare, O. (2015) Susceptibility Patterns of Staphylococcus Aureus Isolates from Clinical Specimens to the Penicillin's. International Journal of Life Sciences Research, 3, $149-153$

\section{Submit or recommend next manuscript to SCIRP and we will provide best service for you:}

Accepting pre-submission inquiries through Email, Facebook, LinkedIn, Twitter, etc. A wide selection of journals (inclusive of 9 subjects, more than 200 journals) Providing 24-hour high-quality service User-friendly online submission system Fair and swift peer-review system Efficient typesetting and proofreading procedure Display of the result of downloads and visits, as well as the number of cited articles Maximum dissemination of your research work

Submit your manuscript at: http://papersubmission.scirp.org/ Or contact ojog@scirp.org 